\title{
Philosophy of Technology Design: Creating Innovation and Added Value
}

\author{
Mohammed Ali Berawi ${ }^{*}$
}

${ }^{1}$ Faculty of Engineering, Universitas Indonesia, Kampus UI Depok, Depok 16424, Indonesia

Technology development is an important means of improving economic and sociocultural conditions. It transforms our knowledge into an artifact that can be used to modernize our civilization and improve our quality of life. Moreover, companies must be innovative to survive and remain competitive; thus, they must exploit their capabilities through the development and use of innovation programs and techniques.

Technological innovation starts with idea generation, and the relationship between innovation management and idea generation often requires a multi-disciplinary team to develop a shared understanding of the relationships between thoughts and reality. If we could improve this, then we could enhance our ability to create value.

\section{Technology Design}

The design process is a series of steps to translate functional requirements into design specifications that say what an artifact should be able to do. In technological design, modeling is an important step in artifact creation and innovation.

Here, I would like to stress that the difference between the function and process of an artifact is a point where the concepts we use must be precise. The implied functional and process theories in artifact development are different in the sense that the first is conceptual and the second is phenomenological in the real world. We must determine an artifact's function in terms of intentionality and how that can be achieved through causal relationships.

In philosophical literature, the concept of function can be divided into two main understandings: teleological and etiological theories. The teleological theory of function explains the purpose and requisite actions of an object by citing expectations of collective intentionality. For example, we all argue a hammer should be used to hit nails. The starting point is to differentiate the purpose of the artifact from the way it is used by articulating the designer's intentionality. Thus, we can explain why and when an artifact (e.g., a chair) can be used in relation to its function; for example, whether a chair can be used to support the weight of a seated person, to hold the door open, as a step-up tool, and so on. An etiological function in a technological artifact explains a causal relationship between why the artifact exists according to an historical account of its adapted/ evolved form. Therefore, we can see the designers' intentionality is constrained within etiological interactions.

On the other hand, a process can be a naturally occurring or a designed sequence of operations or events, possibly needing time, space, expertise, or some other resource to 
produce some phenomenological outcome. A process may be identified by changes it creates in the properties of one or more objects under its influence. The people queuing at a checkout in a bank, a bus stopping at a station, and the operation of an engine are all examples of processes. A need arises in complex design to untangle the design team's intentionality and why they believe various things should become a process-driven solution.

\section{Innovation and Added Value}

Central to a richer understanding is that essential functions must be performed to achieve selected outcomes. Functions are performed by processes; for instance, a car engine's function of "transmit torque" is performed by the processes of a particular engine type. By differentiating between different idea types, we can consider alternative kinds of engines, such as a petrol engine, a diesel engine, or a hybrid engine, all of which perform the same function of "transmit torque." "New" ideas can arise in two ways: first, by searching for additional functions that differentiate products and services, and second, by improving processes currently in use to perform a desired function or by removing unwanted byproducts such as car pollution.

Processes that make no essential contribution can be removed because they have no value. Value results from the efficient and effective working of a system. The interconnected relations between "function," "process," and "outcome" are designed to achieve the intended "purpose." Every function provides an essential contribution to a system, and all processes should have at least one function that justifies their inclusion. The value of a process can be measured in terms of how well it performs essential functions and achieves the desired purpose. A television is a series of processes that perform functions such as displaying moving pictures with sound. Having this function allows us to innovate further and produce hand-held mobile televisions, video-enabled mobile phones, etc. The transformation of function-directed causal relations into manufacturing makes it possible to bridge the gap between physical structure and intentional function in a technological design.

Identifying essentiality in relation to functions, processes, purposes, and outcomes enables us to articulate solutions. Identifying functions enables us to propose alternative ways or processes to perform those functions in the act of idea generation. An "extended function" sets a new context (purpose and goal) for a system. The ability to consider alternative ways or processes that could perform the same essential work with added benefits stimulates inquiry and further exploration of the origin of ideas. This is what I argue is the source of innovation and added value of artifact development.

\section{Accelerating Science and Technology Development}

Technology has been invented to improve projects, products, or the performance of services for our benefit. This edition, we are pleased to present twenty selected papers dedicated to technology development in science and engineering.

The first paper, written by J.A. Cano, F. Salazar, R.A. Gómez-Montoya, and P. Cortés, investigates the use of technologies in Industrial Revolution 4.0 that support logistics management and supply chain processes. The authors argue that the technologies reduce costs, improve stakeholder collaboration, increase the visibility and traceability of products and information, and support the decision-making process.

The next paper, written by S. Candra, M. Ayudina, and M.A. Arashi, determines the online purchase intention and actual buying of food and beverages using an online food application during the Covid-19 pandemic. The authors argue that subjective norms, e-service quality, and health consciousness had an impact on online purchase intentions.

The third paper, written by N.I. Syafii, M. Ichinose, E. Kumakura, S.K Jusuf, W.N. Hien, K. Chigusa, and Y. Ashie, evaluates the unique effects of different water pond configurations. 
The authors argue that larger water pond surfaces tend to produce a better thermal environment, while equally distributed water ponds seem to influence a wider area.

The fourth paper, written by F. Aldiamar, M. Irsyam, B. Hutapea, E. Susila, and Desyanti, evaluates pressure prediction for earth pressure balance (EPB) using analytical and 3dimensional finite element modeling. The authors argue that the model can be used to predict the mean value of face support pressure and the upper and lower perimeters for tunnel construction.

The fifth paper, written by M. Miharja, J. Woltjer, S. Arsallia, and A.H. Diab, examines the perceptions of transaction costs in Indonesian metropolitan transportation planning. The authors argue that the elements of transaction costs involve re-establishing supra-regional institutions and promoting regional development through private sector-coordinated participation.

The next paper, written by N.D. Ulhaq and R. Andayani, investigates the specific surface area of aggregate in a constant water-cement ratio. The authors argue that the isoresponse of slump as a function of specific surface area of aggregate and cement paste-aggregate ratio can be used to predict the slump of a mixture.

The seventh paper, written by O.M. Oyewola, S.I. Oloketuyi, I. Badmus, 0.0. Ajide, F.J. Adedotun, and 0.0. Odebode, proposes a virtual laboratory for the study of centrifugal pump cavitation and performance in a pipeline network. The authors argue that the virtual laboratory is a good training environment that enables precise matching of pipelines to pump flow.

The eighth paper, written by I.K.A.P. Utama, Sutiyo and, K. Suastika, investigates the effect of the axe-bow to reduce total ship resistance on monohull ships. The authors argue that in the trimaran mode with variations of $\mathrm{S} / \mathrm{L}=0.3$ and 0.4 , the mainhull with the axebow helps to reduce resistance up to $8.4 \%$.

The next paper, written by D. Djuhana, C. Kurniawan, D.H. Kim, and A.T. Widodo, investigates the domain structure transition in ferromagnetic nanospheres at ground-state conditions under zero external magnetic field by micromagnetic simulation. The authors argue that magnetization dynamics are an important step in material selection for granular magnetic-based storage.

The tenth paper, written by A.D. Shieddieque, Mardiyati, R. Suratman, and B. Widyanto, examines the characterization of composites reinforced with Sansevieria trifasciata fiber (STF) for automotive applications. The authors argue that the mechanical properties of the biocomposites rise with increasing amounts of fiber, alkaline treatment, and unidirectional fiber orientation.

The eleventh paper, written by A. Wibowo, A. Jatmiko, M.B Ananda, S.A. Rachmawati, H. Ardy, A.H. Aimon, and F. Iskandar, presents polyelectrolyte complex (PEC) nanoparticles using a simple mixing method of chitosan and poly-2-acrylamido-2-methylpropane sulfonic acid. The authors argue that PECs with a chitosan concentration are the most promising drug carrier materials due to their negative surface charges.

The next paper, written by F.F. Lubis, Mutaqin, A. Putri, D. Waskita, T. Sulistyaningtyas, A.A. Arman, and Y. Rosmansyah, proposes automated short-answer grading using semantic similarity based on word embedding. The authors argue that the semantic similarity approach showed a correlation value of 0.70 and an MAE of 0.70 when compared with the grading reference.

The thirteenth paper, written by A. Ocieczek, H. Makała, and A. Flis, compares the sorption properties of four dietary fiber preparations made of cereals (wheat and oats), vegetables (carrot), and root plants (potato). The authors argue that the material types and parameters of the micronization process affect the microstructure of a finished dietary fiber preparation. 
The fourteenth paper, written by N. Amir, M. Efendy, Y.J. Yoo, and M. Gozan, examines the effects of hot air drying on salt quality and energy consumption. The authors argue that the lowest energy consumption and highest energy efficiency while maintaining high salt quality are achieved at $70^{\circ} \mathrm{C}$ with an air velocity of $22.5 \mathrm{~m} / \mathrm{s}$ and a drying time of $30 \mathrm{~min}$.

The next paper, written by H. Herawati, E. Kamsiati, and Sunarmani, discusses the effect of several types of additives on the physical and chemical characteristics of gluten-free noodle products derived from cassava flour. The authors argue that different types and concentrations of additional ingredients could increase the levels of protein and fat in the noodles.

The sixteenth paper, written by N.Z. Zahari, Ng.S. Fong, F.N. Cleophas, and S.A. Rahim, investigates the potential of Pistia stratiotes in the phytoremediation of selected heavy metals from simulated wastewater. The authors argue that $P$. stratiotes uses rhizofiltration as its phytoremediation uptake mechanism.

The next paper, written by K.T. Basuki, M. Fatuzzahroh, D. Ariyanti, and A. Saputra, investigates the adsorption of strontium from an aqueous solution by $\mathrm{TiO}_{2}$-pillared zeolite. The authors argue that the best parameters for strontium adsorption are found to be $\mathrm{pH} 5$ and a contact time of 80 min.

The eighteenth paper, written by N.S.R Rosman, M.A.A Masimen, N.A. Harun, I. Idris, and W.I.W Ismail, presents an optimization of biogenic silver nanoparticles (AgNPs) synthesized from marine polychaete (M. moribidii). The authors argue that the green synthesis of AgNPs utilizing marine invertebrates as reducing and stabilizing agents offers many advantages.

The nineteenth paper, written by M.D.P.T.G Puteri, E. Kato, D. Rahmawati, S. Teji, J.A. Santoso, F.I Pandiangan, and Y.A. Nion, examines the post-harvest and extraction conditions for the optimum alpha glucosidase inhibitory activity of Stenochlaena palustris. The authors argue that the smaller particle size of dried $S$. palustris powder provides better extraction of the AGI component.

The last paper, written by I. Yuniarti, E.F. Sapatra, S.F. Novia, Hovivah, V. Paramita, and M.E. Yulianto, determines the effects of adding natural papain enzyme to virgin coconut oil (VCO)-based hand and body lotions with added orange peel extract. The authors argue that the highest yield of VCO, at $13.8 \pm 5.30 \%$, is obtained using a $45 \%$ papain enzyme extract.

I hope that this edition of IJTech conveys some new insights into the way we conduct our research. I am pleased to accept and respond to any comment or inquiry you may have on the direction and content of IJTech, and I invite you to join us in this venture by sending your work for consideration.

With warmest regards from Jakarta,

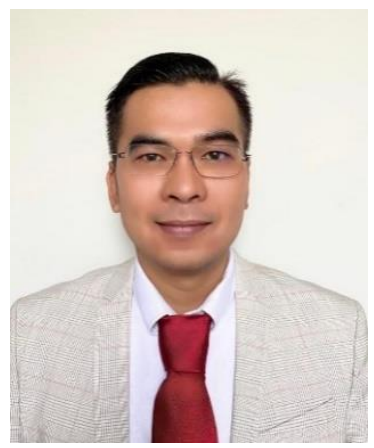

Dr. Mohammed Ali Berawi Editor in Chief 